\title{
Electrochemical Cysteine Sensor on Novel Ruthenium Based Ternary Catalyst
}

\author{
Hilal Kivrak ${ }^{1,2, *}$, Kadir Selçuk ${ }^{2}$,Omer Faruk Er ${ }^{2}$, Nahit Aktas $^{2,3 *}$ \\ ${ }^{1}$ Eskisehir Osmangazi University, Faculty of Engineering and Architectural Sciences, Department of \\ Chemical Engineering, Eskişehir, 26040 Turkey \\ ${ }^{2}$ Van Yuzuncu Yil University, Faculty of Engineering, Department of Chemical Engineering, \\ Van,65000 Turkey \\ ${ }^{3}$ Kyrgyz-Turk Manas University, Faculty of Engineering, Department of Chemical Engineering, \\ Bishkek, Kyrgyzstan \\ *E-mail: hilalkivrak@gmail.com, nahit.aktas@manas.edu.kg, naktas@yyu.edu.tr
}

doi: $10.20964 / 2021.05 .48$

Received: 21 January 2021 / Accepted: 16 March 2021 / Published: 31 March 2021

\begin{abstract}
At present, a voltammetric L-Cystein (Cys) sensor is developed based on carbon nanotube (CNT) supported Ru-Mo-Pd trimetallic catalyst modified glassy carbon electrodes (GCE). Firstly, Ru-Mo/CNT catalysts are prepared via sodium borohydride reduction method and following this Ru-Mo/CNT modified GCE electrode is prepared and Pd electrodeposition at varying Pd concentrations is performed to obtain Ru-Mo-Pd/CNT catalysts. Ru-Mo-Pd/CNT catalyst is characterized by TEM and SEM-EDX. Characterization results reveal that $\mathrm{Ru}-\mathrm{Mo}-\mathrm{Pd} / \mathrm{CNT}$ catalyst is succesfully synthesized. For electrochemical measurements, GCE is modified with $\mathrm{Ru}-\mathrm{Mo}-\mathrm{Pd} / \mathrm{CNT}$ catalysts and electrochemical behavior of the modified GCE is investigated by cyclic voltammetry, differential pulse voltammetry, electrochemical impedance spectroscopy. Ru-Mo-Pd/CNT at $0.0152 \mathrm{mM} \mathrm{Pd}$ concentration modified GCE electrode have the best Cys electrooxidation activity. Hence, further electrochemical measurements to determine sensitivity, limit of detection, intereference study, and real sample are performed on RuMo-Pd/CNT at $0.0152 \mathrm{mM}$ Pd concentration modified GCE electrode. This sensor has a wide linear response within the range of $5-200 \mu \mathrm{M}$ with high current sensitivity $0.136 \mu \mathrm{A} / \mu \mathrm{M}$ and $0.1 \mu \mathrm{M}$ as lowest detection limit at $(\mathrm{S} / \mathrm{N}=3)$ signal to noise ratio. Interference studies reveal that $\mathrm{Ru}-\mathrm{Mo}-\mathrm{Pd} / \mathrm{CNT}$ sensor is not affected by common interfering species. This novel study reports a strategy to sense Cys on $\mathrm{Ru} / \mathrm{CNT}$ modified GCE electrode.
\end{abstract}

Keywords: Cysteine; Ruthenium; Palladium; Molybdenum; electrochemical; sensor $\underline{\text { FULL TEXT }}$ 
(C) 2021 The Authors. Published by ESG (www.electrochemsci.org). This article is an open access article distributed under the terms and conditions of the Creative Commons Attribution license (http://creativecommons.org/licenses/by/4.0/). 